\title{
The effectiveness of guilt and shame appeals on health communications: The moderating role of self-construal and personal cultural orientation
}

\author{
Hoang Sinh Nguyen ${ }^{\mathrm{a}}$, Daniel Laufer ${ }^{\mathrm{b}}$, Jayne Krisjanous ${ }^{\mathrm{b}}$ \\ a School of Business Administration, Ho Chi Minh City Open University, Ho Chi Minh City, Vietnam \\ ${ }^{\mathrm{b}}$ Wellington School of Business and Government, Victoria University of Wellington, Wellington, New Zealand
}

\section{A R T I C L E I N F O}

\section{Article history:}

Received 4 July 2019

Revised 23 July 2020

Accepted 5 August 2020

Available online $\mathrm{xxx}$

Nguyen Hoang Sinh (Ph.D., Victoria University of Wellington), is a lecturer in marketing and Head of Marketing Department, School of Business Administration, Ho Chi Minh City Open University.

\section{Keywords:}

Guilt

Shame

Self-construal

Personal cultural orientation

Binge drinking

Health communications

Self-conscious emotion

\begin{abstract}
A B S T R A C T
This study examines the moderating effects of self-construal and personal cultural orientation on the relationships between guilt and shame appeals and health message compliance. Binge drinking is chosen as the health issue for this study and a between-subjects experiment $(n=301)$ was conducted to test the model. The study makes several contributions to the literature of communications using guilt and shame appeals by exploring conditions under which such appeals are more effective. The main effect of self-construal on guilt/shame arousals was found, but no interactive effect with referencing or sources of evaluation. The effect of personal cultural orientation, which has been under-researched in the guilt and shame emotions, on message compliance supported an interactive effect with emotion type. Novelly, the methodological value of this research is in the study of response/emotional arousal from the stimulus, not the stimulus/appeal itself.
\end{abstract}

(C) 2020 Australian and New Zealand Marketing Academy. Published by Elsevier Ltd. All rights reserved.

\section{Introduction}

Message appeals (rational and emotional) are important factors in how messages are attended to and interpreted by a receiver (Flora and Maibach, 1990; Martin and Lawson, 1998; Parrott, 1995). Emotion-based appeals are common (de Hoog et al., 2005; Dickinson and Holmes, 2008; 2011; Pechmann et al., 2003; Schoenbachler and Whittler, 1996). Negative emotional appeals are most frequently used (Agrawal and Duhachek, 2010; Arthur and Quester, 2003; Keller and Lehmann, 2008; Keller et al., 2003) because they can create an emotional discomfort that can be remedied by engaging in the featured behavior. Along with fear (primary emotion), guilt and shame (self-conscious emotion) appeals may be used in social marketing messages owing to their presumed ability to motivate socially desirable behaviors (Brennan and Binney, 2010). Although the effectiveness of guilt appeals has been substantially explored in pro-social or charitable donations, that of guilt and especially shame appeals in health communications remains relatively unexplored (e.g., Duhachek et al., 2012; Becheur et al., 2019; Boudewyns et al., 2013; Han et al., 2014; Netemeyer et al., 2016). Indeed, a recent meta-analysis in the health domain is conducted with only eight guilt appeal studies (Xu and Guo, 2018). Further, in studies comparing guilt and shame, researchers examined guilt and shame appeals together rather than separating guilt versus shame appeals via their distinct emotional arousals (Duhachek et al., 2012; Boudewyns et al., 2013; Han et al., 2014). For example, in three studies in a drinking context, Duhachek et al. (2012) investigated the interactive effect of guilt versus shame emotions with gain and loss framing on persuasion via alcohol advertising (emotional appeals). Therefore, the current research differentiates the two emotions by directly examining emotional arousal/response rather than emotional appeal/stimulus itself.

E-mail address: sinh.nh@ou.edu.vn (H.S. Nguyen). 
It is noted that the pro-social or charitable donations context differs from the health communications context. That is, at the individual level, the former involves motivating people for the benefit of others while the latter involves stimulating people for the benefit of themselves (Hoek and Insch, 2011). As a result, in the health communications context, guilt and shame appeals may operate differently due mainly to the interaction between the selfreferential type of such emotions and the personal significance in the context. In light of this gap, this study examines the effectiveness of guilt and shame appeals on health communications.

Health messages can challenge individuals' views of themselves as "adaptively and morally adequate" (Leary and Baumeister, 2000, p. 262), leaving them with feelings attributed to guilt and shame. In this regard, therefore, guilt and shame can feasibly be used directly as appeals in health messages to motivate positive behaviors because of a threat posed to personal notions of self-integrity. While a growing literature has endeavored to characterize the psychological processes involved in guilt and shame, often focusing on the distinct antecedents and their consequences for social behaviors, there is little understanding of how (e.g., mediator) and when (e.g., moderator) guilt and shame appeals in health communications can encourage the healthy behavior. This is partly due to the lack of research into the distinction between guilt and shame appeals and the key moderators that are influential in the response to them, which motivate positive behaviors. Therefore, this research focuses on the effectiveness of guilt and shame appeals on health communications by, firstly, examining the difference between guilt and shame arousals.

A number of studies have examined the effectiveness of guilt and/or shame appeals, but they largely focused on message characteristics as moderators. There is evidence that individual and cultural characteristics may influence message compliance in response to guilt and shame arousals. For example, an increasing body of literature suggests that the valuation, eliciting, and behavioral consequences of these self-conscious emotions differ across cultural contexts because of the type of self-construal that is promoted in one's cultural context (Lee and Paek, 2014; Wong and Tsai, 2007). That is, in contexts that promote an independent self (e.g., Western cultures), guilt is one of the valued emotions; however, in contexts that promote an interdependent view (e.g., Eastern cultures), shame is perceived more positively. Specifically, in a collectivist culture shame can lead to adaptive outcomes (Bagozzi et al., 2003; Scollon et al., 2011; Silfver, 2007; Wong and Tsai, 2007). Thus, shame is self-regulated differently across cultures, and leads to differential effects on behavioral responses. Consequently, the role of culture, especially at the individual level (e.g., personal cultural orientation, Yoo and Donthu, 2005), is important in guilt and shame appeals, but this role is under-studied.

From a cross-cultural perspective, self-construal is defined as "a constellation of thoughts, feelings, and actions concerning the relationship of the self to others, and the self as distinct from others" (Singelis and Sharkey, 1995, p. 624). While it is a more dynamic individual characteristic (Aaker and Lee, 2001; Levinson et al., 2011), studies on self-construal are typically conducted through a chronic cultural characteristic such as ethnicity (Block, 2005; Kim and Johnson, 2014). For instance, in Block's (2005) studies on the persuasiveness of fear and guilt appeals, the 'self-construals' were grouped into two kinds based on participants self-identifying as American or Asian. Explaining the influence of self-construal as the dynamic individual characteristics of independence versus interdependence provides a new approach for examining cross-cultural differences in self-conscious emotions.

Thus, the current research investigates the effectiveness of guilt and shame appeals on health communications by, secondly, directly examining self-construal and personal cultural orientation. Self-construal and personal cultural orientation are assumptions frequently made in the cross-cultural literature (Bagozzi et al., 2003; Kitayama et al., 2006; Yoo and Donthu, 2005). The assumptions are that culture determines self-construal and that individuals from different cultures have reliable differences in personal cultural orientation. Therefore, it has the potential to expand our knowledge of how guilt and shame function across cultures.

In all, the study has several contributions. Theoretically, a significant contribution of the research is to identify boundary conditions on self-construal and personal cultural orientation guilt versus shame effects. Practically, the study differentiates between guilt and shame because health communications researchers and practitioners commonly use the terms 'guilt' and 'shame' interchangeably (Boudewyns et al., 2013; Han et al., 2014). Methodologically, this study examines guilt and shame separately via the distinct emotional arousals of guilt versus shame, rather than emotional appeals. It is possible that guilt appeals have unintentionally elicited shame, which might account for some of the unintended effects that have been found in the literature (Bennett, 1998; Boudewyns et al., 2013). By isolating the effect of an unintended emotion aroused from the appeal, the present study makes findings consistent and generalizable. Thus, the methodological value of the current research is in the study of response/emotional arousal from the stimulus, not the stimulus/appeal itself.

\section{Literature review}

\subsection{Guilt versus shame}

Guilt is a negative emotion that occurs when a person believes his/her behavior has violated personal or social standards (O'Keefe, 2002). Guilt appeals have been shown to influence attitudes and intentions, but there is debate regarding when they are most effective. Early studies have found that highly intense guilt appeals often cause anger and are less persuasive (referred to as an inverse-U relationship; Coulter and Pinto, 1995), while moderately intense guilt appeals can elicit guilty feelings, thereby motivating people to change attitudes about a given product/offer (Coulter et al., 1999; Coulter and Pinto, 1995; O'Keefe, 2002). However, recent studies testing guilt appeals in both the pro-social and commercial realm attest to the effectiveness of intense guilt appeals (Cotte et al., 2005; Lindsey, 2005; Turner and Underhill, 2012) such that they did not support the inverse-U effect but rather supported a linear effect. This claim, further supported by Boudewyns et al. (2013), proposed that guilt is not correlated with anger, but rather that shame is associated with anger.

Despite often being used interchangeably, shame differs from guilt. Shame is a painful emotion aroused when the self is perceived to be defective, unworthy and disgraceful (Lewis, 1992). Shame is associated with anger and even aggression, which has been empirically supported by social psychology studies (Bennett et al., 2005; Stuewig et al., 2010; Tangney and Dearing, 2002). For instance, Tangney and Dearing (2002) found that while anger has been positively associated with shame-proneness, it has been negatively associated with guilt-proneness. However, studies in communications have not only supported the claim that shame is associated with anger, but also raised the issue of confusion between guilt and shame appeals (Bennett, 1998; Boudewyns et al., 2013). Most importantly, Bennett (1998) suggested that messages designed to elicit highly intense levels of guilt may actually evoke shame feelings unintentionally. Similarly, Boudewyns et al. (2013) claimed that the highly intense guilt appeals that lead to anger actually evoked a combination of shame and guilt, or shame only. Some guilt appeals are actually shame appeals and this may provide a reason why intense guilt appeals are ineffective. For instance, Coulter and Pinto's (1995) guilt appeal for dental floss stated: "It's YOUR responsibility to make sure 
that your kids have healthy teeth and gums. The pressure is on YOU, so don't make any mistakes... DO IT RIGHT!" (p. 700). Clearly, the stimulus seems to emphasize the word 'you' that implies the person instead of the behavior; as a result, the guilt appeal results in shame rather than guilt (Lewis, 1971). Therefore, more research is needed to fully understand the effects of guilt and shame separately.

Guilt and shame are distinct and have differential effects in encouraging compliance. Guilt tends to create more favorable behavioral responses, but shame is more likely to trigger negative behaviors (Abe, 2004; Gausel and Brown, 2012; Lindsay-Hartz, 1984). In social psychology, shame is a potent experience that plays an important role in normal development of both adaptive and maladaptive behaviors. Adaptively, shame essentially helps to motivate socially favorable behavior and efforts towards self-improvement (de Hooge et al., 2010; Gausel and Leach, 2011; Sznycer et al., 2016). However, when shame becomes a dominant emotion, it can lead to maladaptive outcomes (Gilbert, 1998; Kaufman, 1996; Mills, 2005; Schore, 1998). Remarkably, the damaging aspects of shame are recognized consistently in psychology, but evidencebased interventions in health communications are noticeably absent (Boudewyns et al., 2013). While a significant number of studies supporting the development of guilt theory in the literature exist (Brennan and Binney, 2010; Leshner et al., 2009), the theory of shame, especially in health communications, is underdeveloped.

\subsection{Self-construal}

The independent self is emphasized more in individualist cultures, whereas the interdependent self is represented more often in collectivist cultures (Cross et al., 2011). While self-construal is imposed by culture, self-conscious emotions are sensitive to self-construal differences. Indeed, several researchers suggest that a different construal of the self leads to different self-conscious emotions, as these emotions rely on self-awareness and selfevaluations (Tracy and Robins, 2007a, 2007b). Nationally, collectivist cultures favored shame emotion while individualist cultures, guilt emotion (Creighton, 1990). This is because in individualist cultures, people rely on an internalized sense of right and wrong to control behavior; collectivist cultures, on the other hand, rely on people's concerns about how they look to others (Sabini and Silver, 1997).

Research in self-construals implies that the attributions that elicit guilt and shame emotions may be additional manifestations of prevailing motivational tendencies for maintaining positive distinctiveness, in the case of independent self-construals, and maintaining social connectedness, in the case of interdependent selfconstruals (Dean and Fles, 2016). Independent self-construals are expected to attempt to be unique, to promote their own personal goals, more sensitive to personal responsibility, and independent from others (Markus and Kitayama, 1991). It is assumed that in a guilt appeal, an internalized sense of moral responsibility is the salient feature. Since independent people feel a greater sense of right and wrong, a guilt appeal making personal responsibility and accountability more salient will create an elevated response, compared to interdependent people (Becheur et al., 2019). Thus, it can be expected that, given exposure to the same guilt appeal, independent self-construals will experience the emotion more intensively.

H1(a): For individuals with high independent self-construals, guilt appeals lead to higher arousal.

People with a chronic and salient interdependent view readily accept negative self-relevant information and use it as the basis for future self-improvement (Heine et al., 2001), and interdependent self-construals are expected to be concerned with ongo- ing relationships. They are also expected to maintain interdependence, to perform their part of group actions on the job, to adjust to and fit into their groups and relationships, and in general to promote group welfare. When shamed, interdependent people become aware that their actions or performances are negatively evaluated and come to feel that their self has been degraded and ridiculed (Bagozzi et al., 2003). It would be argued that when exposed to the same shame appeal interdependent self-construals might experience shame more intensively.

H1(b): For individuals with high interdependent self-construals, shame appeals lead to higher arousal.

\subsection{Self-construal interacting with referencing and sources of evaluation}

Referencing is defined as a cognitive process where audiences relate message information to either the self or the other (Burnkrant and Unnava, 1995). Accordingly, there are two types of referencing (Block, 2005, p. 2031): self-reference (i.e., "The more YOU drink, the more coordination YOU lose...") and other-reference ("The more PEOPLE drink, the more coordination THEY lose...").

Research shows that the relative intensity of guilt may vary depending on determined conceptions of referencing (Block, 2005; Meyers-Levy and Peracchio, 1996). That is, individuals who view a self-referenced guilt appeal involving an unpleasant, negative health-related event, and are told that they are responsible for its occurrence, will experience guilt more intensively compared to an other-referenced appeal involving others' responsibility (i.e., the self-reference effect, Block, 2005). Further, whether self-referenced emotional appeals are more or less arousing also may depend on individuals' independence versus interdependence (i.e., selfconstrual) (Aaker, 2000; Murray-Johnson et al., 2001; Williams and Aaker, 2002). It is therefore proposed that not only do selfreferenced guilt appeals arouse guilt more intensively than do other-referenced guilt appeals, but this effect is also influenced by independent or interdependent self-construal.

For people with independent self-concepts, Block (2005) suggested that the self-reference effect is either advantageous or disadvantageous depending upon the centrality of the self in the emotion that is elicited from a health message. Attributions of causality to the self versus the other in the independents create different levels of perceived guilt. A study reported that people who have independent self-concepts felt guilty when they recognized they had violated their own personal standards, while people who have interdependent self-concepts felt guilty when they recognized that their wrongdoings hurt others (Stipek et al., 1989). Thus, it is argued that, for independents who perceive the self as a separate and distinct entity, the self-reference effect should be more prominent in perceived guilt than for people with interdependent self-concepts. The self-reference effect will accordingly be obtained when independents process the guilt appeals.

H2(a): For individuals with high independent self-construals, levels of emotional arousal elicited from a guilt appeal are impacted by referencing. Specifically, they will exhibit higher guilt arousal for a self-referenced appeal than for an other-referenced appeal.

Research indicates that both imagining oneself and receiving aversive information diminishes the likelihood of the self-reference effect (Lord, 1980; Sedikides and Green, 2000). Since a shame appeal in health messages relies on the social sanction of an imagined negative consequence to the self, the mentioned reversed selfreference effect has suggested that self-referenced shame appeals would be less influential than other-referenced for people with independent self-construals. 
As Lord (1980) reported, the self (independent self-construal, in this case) could not have superior memory advantage for imagined representations of the self as compared to propositional representations of the self. In this case of anticipated shame, the otherimage is more effective in memory for the self than the self-image because of perceptual salience. Besides, the negative valence of shame appeals also reduces the effect of self-reference. Taken together, the self-reference effect could be reversed when people with a primarily independent view of self process an anticipated shame appeal. Thus it could be argued that, for independent selfconstruals, the other-referenced shame appeals lead to more intense shame than do the self-referenced.

H2(b): For individuals with high independent self-construals, levels of emotional arousal elicited from a shame appeal are impacted by referencing. Specifically, they will exhibit higher shame arousal for an other-referenced appeal than for a selfreferenced appeal.

Guilt and shame both have internal and external sources of evaluation (Brommersma, 2007; Gilbert et al., 2007; Kim et al., 2011). For example, internal guilt occurs when the transgressor is the only person who knows of the breach of conduct (i.e., the self's observation), external guilt occurs when a transgression is known to others (e.g., friends, family members, i.e., the others' observation) (Baumeister et al., 1994). Similarly, while internal shame is related to experiences in which the self is devalued in one's own eyes and self-identity is harmed, external shame is associated with the belief that others look down on the self and see the self as inferior, inadequate, disgusting or weak in some way (Gilbert, 1998).

Research indicates that the impact of internal and external sources of evaluation for experienced guilt and shame on message processing is moderated by self-construal (Kim and Johnson, 2013; Wong and Tsai, 2007). According to Wong and Tsai (2007), an assumption of prevailing models of guilt and shame states that internal orientation (e.g., oriented to one's own standards/view) is more powerful and genuine than external orientation (e.g., oriented to others' standards/view) in the case of the self that is distinct, separate from others, which is referred to as an independent selfconstrual. For independents, therefore, the internal source of evaluation should be more pronounced in perceived guilt and shame than the external one.

Accordingly, for guilt, the internal source of evaluation will be more powerful when independent self-construals process the appeals. That is, the internal guilt appeals lead to more intense guilt than do the external guilt appeals.

H3(a): For individuals with high independent self-construals, levels of emotional arousal elicited from a guilt appeal are impacted by the evaluation source. Specifically, they will exhibit higher guilt arousal for an internal appeal than for an external appeal.

Similarly with guilt, for independents, who are predisposed to viewing the self as a separate and distinct entity, the internal source of evaluation should be more pronounced in perceived shame than the external one (Kim and Johnson, 2013; Wong and Tsai, 2007). Accordingly, for shame, the internal source of evaluation will thus be more powerful when independent self-construals process the appeals. That is, the internal shame appeals lead to more intense shame than the external shame appeals.

H3(b): For individuals with high independent self-construals, levels of emotional arousal elicited from a shame appeal are impacted by the evaluation source. Specifically, they will exhibit higher shame arousal for an internal appeal than for an external appeal.
However, for people with interdependent self-concepts, there is no self-construal interacting with referencing and sources of evaluation. That is, referencing and sources of evaluation are equally persuasive regardless of self-conscious emotional types (Aaker and Williams, 1998; Block, 2005).

Indeed, Aaker and Williams' (1998) studies on the persuasiveness of ego-focused (e.g., pride) versus other-focused (e.g., empathy) emotional appeals found that the self-reference effect was not obtained for interdependent self-construals across the two emotions. That is, for individuals with interdependent self-construals, the self-referenced and other-referenced appeal was equally favorable in terms of brand attitudes regardless of emotional types. This means that referencing has no effect for those interdependent people who experience guilt or shame. Further, it would be argued that for interdependent people, the internal versus external sources of evaluation are equally persuasive across the two emotions. That is because individuals with interdependent perceptions of the self view themselves in terms of their connections with others; the external influences (other people's thoughts and feelings) are as important and meaningful as the internal ones (one's own thoughts and feelings) (Wong and Tsai, 2007). This means that the source of evaluation has no effect for those interdependent people who feel guilt or shame. This leads to the following questions due to a lack of empirical evidence.

Q1: For individuals with high interdependent self-construals, does referencing impact levels of emotional arousal elicited from a (a) guilt appeal or (b) shame appeal?

Q2: For individuals with high interdependent self-construals, does the evaluation source impact levels of emotional arousal elicited from a (a) guilt appeal or (b) shame appeal?

\subsection{Guilt and shame arousals}

The link between emotional arousal, attitude formation and behavioral compliance is theoretically supported (e.g., Brennan and Binney, 2010). Thus, social marketers often use emotional appeals in an attempt to encourage compliant behavior from the public (Han et al., 2014). However, there are mixed findings regarding emotions in general. Some fear studies found no relationship between emotional arousal and behavioral intention (Rogers, 1975; Schoenbachler and Whittler, 1996), while others found that stronger emotional responses lead an individual to using an adaptive response (Folkman et al., 1979; Tanner et al., 1991) and ultimately to message compliance (Ang and Low, 2000; Lee et al., 2000). As noted previously, distinct guilt and shame are under studied. This research examines the impact of guilt and shame arousals (rather than emotional appeals) on message compliance.

Early studies have found the inverse-U relationship in guilt intensity and message persuasion (Coulter et al., 1999; Coulter and Pinto, 1995; O'Keefe, 2002). However, recent studies testing guilt messages in both the pro-social and commercial realms attest to the effectiveness of intense guilt levels (Cotte et al., 2005; Lindsey, 2005; Turner and Underhill, 2012). Such that, they did not support the inverse-U effect but rather they supported a linear effect. Research focused on charitable donations indicates that people who experience guilt tend to want to make reparations for the harm that has been done to others and want to avoid actions that might result in guilty feelings (Hibbert et al., 2007; Lwin and Phau, 2014). Taken together, there is strong evidence to suggest that any intense guilt arousals can evoke positive behavior. It is thus assumed that there is a strong positive relationship between guilt arousals and behavior intentions.

In comparison with guilt, shame tends to create more defensive responses (Abe, 2004; Lindsay-Hartz, 1984; Stuewig et al., 2010). 
However, in social psychology, shame essentially helps to motivate socially favorable behavior and efforts towards self-improvement (de Hooge et al., 2010; Gausel and Leach, 2011; Sznycer et al., 2016). In fact, shame is associated with a greater desire to change aspects of one's self implicated in a past transgression (Gausel and Brown, 2012); activates approach action tendencies, manifesting as pro-social behavior like directly repairing social errors (de Hooge et al., 2010); and deters actions that would lead to more devaluation than benefits (Sznycer et al., 2016). This claim is supported in contexts that promote an interdependent view or a collectivist orientation (Bagozzi et al., 2003; Scollon et al., 2011). It is thus hypothesized that there is a positive relationship between shame arousals and message compliance.

H4: The relationship between (a) guilt arousals and message compliance, and (b) shame arousals and message compliance is positive.

\subsection{Personal cultural orientation}

As noted, the intersection of personal cultural orientation and guilt and shame emotions is an increasingly important but understudied area. Most studies of guilt and shame across cultures were based on ethnicity as chronic cultural characteristics rather than personal cultural orientation as dynamic individual characteristics. Thus, this study explores in which personal cultural orientation these two self-conscious emotions will be up-regulated or downregulated.

The influence of shame on coping responses and behavioral intentions depends on the values and beliefs associated with the given culture (Czub, 2013; Silfver, 2007). Kitayama et al. (1995) suggested that the link between shame and defensive reactions, such as anger, is distinctive of individualist cultures where the sense of the independent self is highly appreciated, and where shame can thus be perceived as a sign of weakness. From this perspective, hiding shame with anger is reasonable in individualist cultures, but unreasonable in collectivist cultures. That is because in collectivist cultures where interdependence is highly valued, defending the self against shame in this way would likely be seen as inadequate. Demonstrating shame to others is seen as better, because it helps to maintain relationships and social cohesion. In fact, Bagozzi et al. (2003), comparing Dutch and Filipino salespeople's experiences of shame as a result of customer actions, found that they have similar experiences of shame but the behavioral consequences of the emotion are different. For Filipino salespeople, shame improved customer relationship-building, whereas for Dutch salespeople, shame diminished it. In other words, behavioral intentions with the shame arousal appear to be highly related to cultural orientation.

H5: The impact of shame arousal on message compliance is moderated by personal cultural orientation. Specifically, (a) individualist individuals experiencing shame are less likely to comply with the message, whereas (b) collectivist individuals experiencing shame are more likely to do so.

At the national level, guilt is considered as a more favorable emotion in individualist cultures, resulting in a higher emotional arousal than in collectivist cultures (Eid and Diener, 2001). However, in terms of emotion regulation, empirical studies found that there are not clear cultural differences in guilt feelings (Wallbott and Scherer, 1995). Therefore, it is possible that coping with guilt is unrelated to cultural contexts. Meanwhile, in the dominant models of guilt, regardless of culture, guilt leads to reparative action (Wong and Tsai, 2007). For example, empirical findings in American contexts suggest that experiencing guilt leads to higher self-esteem and increases in empathy and perspective taking (Tangney, 1998). Taken together, feelings of guilt are likely to lead to message compliance for both individualist and collectivist people.

At an individual level, while there is a lack of studies on culture in guilt feelings, cultural orientation is dominantly influenced by national culture (Alegria et al., 2010). Thus, this leads to the following question. Q3: Does personal cultural orientation have an impact on the re-
lationship of guilt arousal and message compliance?

\section{Overview of the research}

The research sets out to examine guilt and shame separately via the distinct emotional arousals of guilt versus shame under the moderating effects of self-construal and personal cultural orientation. To test these propositions, this research has two studies. In study $1 \mathrm{~A}$, an experiment was conducted to provide preliminary evidence that guilt versus shame appeals lead to higher guilt versus shame arousals. Study $1 \mathrm{~A}$ also tests the moderating effect of selfconstrual on the relationships between guilt/shame appeals and arousals. In study $1 \mathrm{~B}$, a survey was used to test the relationships between guilt/shame arousals and message compliance. Study 1B also tests the moderating effect of personal cultural orientation on these relationships. It should be noted that these two studies are from the same research and dataset (Backhaus et al., 2002; Kaiser et al., 1999).

Binge drinking is chosen as the health issue for the current research. This is because alcohol consumption is a significant public health concern and binge drinkers are the focus of many health promotion campaigns (Jefferis et al., 2005). However, it is evident that knowledge of the health risks of binge drinking provided by the campaigns has not translated into a reduction in binge drinking behavior (Johnston and White, 2003; O'Malley et al., 1998).

\subsection{Study $1 A$}

\section{Method}

Participants and design. The study used a 2 (emotional appeal: guilt versus shame) x 2 (referencing: self-referenced versus other-referenced) x 2 (evaluation source: internal versus external) between-subjects experimental design with a control group. 301 undergraduate students from a New Zealand university were randomly assigned to one of the eight stimuli (59.0\% female, $M_{\text {age }}=20.07, S D=2.19$ ).

Stimulus development. Eight stimulus print advertisements were newly developed and identical in content and design characteristics with the exception of the manipulation section to avoid confounding effects (see Appendix 1). Accordingly, the guilt appeal focuses on the behavior of a potentially committed actor (e.g., Binge drinking) and the shame appeal focuses on the self as a potentially committed actor (Irresponsible drinker). Then, each advertisement incorporates referencing or evaluation source types. For the referencing, adopted from Block's (2005) study, the self-referenced guilt/shame appeal references the receiver's behavior/self (You make this wrong decision), while the otherreferenced guilt/shame appeal references the others' behavior/self (Others make this wrong decision). For the evaluation source, the internal guilt/shame appeal mentions the actor's decision will be known/seen by him/herself (You are a sufferer/an observer), while the external appeal mentions the actor's decision will be known/seen by the others (Others are sufferers/observers) (Baumeister et al., 1994; Gilbert et al., 2007). Two images were used in which male participants were exposed to a male image and females to a female image. 
Table 1

Adjusted means of self-construal and type of appeal on guilt/shame arousal.

\begin{tabular}{|c|c|c|c|c|c|c|c|c|c|c|}
\hline & \multicolumn{5}{|c|}{ IndSC } & \multicolumn{5}{|l|}{ IntSC } \\
\hline & \multicolumn{2}{|c|}{ Referencing } & \multicolumn{3}{|l|}{ Source } & \multicolumn{2}{|c|}{ Referencing } & \multicolumn{3}{|l|}{ Source } \\
\hline & Self & Other & Internal & External & Self & Main & Other & Internal & External & Main \\
\hline GAr & 3.07 & 3.39 & 3.70 & 3.02 & $3.36^{*}$ & 2.74 & 3.49 & 2.81 & 2.60 & $2.83^{*}$ \\
\hline SAr & 2.73 & 2.99 & 3.26 & 3.17 & 3.07 & 3.50 & 3.06 & 2.84 & 2.77 & 2.97 \\
\hline
\end{tabular}

Note. ${ }^{*}$ Differ significantly from each other at $p<.05$.

Pretest. To ensure the effectiveness of the manipulation, pretesting was conducted with 261 undergraduate students by asking them to rate statements consistent with prior research on a 7point scale regarding the types of emotional appeal, referencing, evaluation source, and intensity level of emotional appeal.

The type of emotional appeal: "According to the advertisement, what was the focus of binge drinking?" anchored by $1=$ the behavior (for guilt), $7=$ the self (for shame) (Lewis, 1971; Tangney and Dearing, 2002). The difference in ratings on the focus between guilt $(M=3.65)$ and shame $(M=4.18)$ appeal type was significant, $t(259)=-2.045, p=.042$.

The type of referencing: "According to the advertisement, rate the extent to which binge drinking could be committed by..." anchored by 1 =yourself (for self-reference), $7=$ others (for otherreference) (Block, 2005). There was a significant difference in ratings on referencing between self-reference $(M=3.25)$ and otherreference $(M=3.94), t(128)=-2.134, p=.035$.

The type of evaluation source: "According to the advertisement, rate the extent to which the consequences of binge drinking could be known/seen by..." anchored by $1=$ yourself (for internal source), $7=$ others (for external source) (Gilbert et al., 2007; Kim et al., 2011). The difference in ratings on source of evaluation between internal $(M=3.73)$ and external $(M=5.26)$ was significant, $t(129)=-5.230, p=.000$.

The intensity level of emotional appeal: "How successful was the advertisement in attempting to make the viewer feel guilt?"; "How successful was the advertisement in attempting to make the viewer feel shame?" anchored by $1=$ not at all, $7=$ extremely (Coulter and Pinto, 1995). Results show that guilt appeals resulted in significantly more guilt $(M=3.48)$ than shame $(M=3.24), t(127)=2.824$, $p=.005$; shame appeals resulted in significantly more shame $(M=3.83)$ than guilt $(M=3.67), t(130)=2.162, p=.032$.

Manipulation checks. For the referencing and evaluation source, there was a significant difference between self-reference $(M=2.74)$ and other-reference $(M=3.59), t(134)=-2.624, p=.010$, and between internal $(M=3.67)$ and external source $(M=5.09)$, $t(128)=-4.825, p=.000$. For the emotional appeal, the differences in felt emotion across four types of guilt appeal (selfreferenced, other-referenced, internal, external): $F(3,126)=1.632$, $p=.185$ and four types of shame appeal (self-referenced, otherreferenced, internal, external): $F(3,132)=1.222, p=.304$, were not significant. Guilt appeals resulted in significantly more felt guilt $(M=3.95)$ than felt shame $(M=3.63), t(128)=2.636, p=.009$; and shame appeals resulted in significantly more felt shame $(M=4.38)$ than felt guilt $(M=4.17), t(134)=1.981, p=.045$. The differences in emotional arousal between the treatment groups and the control group were significant $(p s<.005)$. The mean score of the treatment groups is significantly higher than that of the control group: $M_{\text {Guilt }}=3.09$ versus $M_{\text {Control }}=1.97$ and $M_{\text {Shame }}=3.04$ versus $M_{\text {Control }}=2.29$. This suggests that manipulation checks were successful.

\section{Results}

Self-construal (SC): Independent (IndSC) versus Interdependent (IntSC). A two-way ANCOVA was performed to examine the effects of SC and type of appeal (referencing, source of evaluation) on guilt/shame arousal (GAr/SAr), after controlling for guilt/shame appeal (GAp/SAp) (see Table 1).

For guilt, after adjusting for GAp, there was significant difference between IndSC and IntSC on GAr, $F(1,127)=4.228, p=.042$. Specifically, the GAr scores for IndSC $(M=3.36)$ are significantly higher than for IntSC $(M=2.83)$. Thus, hypothesis $1(\mathrm{a})$ is accepted. For shame, after adjusting for SAp, there was no significant difference between IndSC and IntSC on SAr, $F(1,133)=.219, p=.641$. Thus, hypothesis 1 (b) is rejected.

The study found the main effect of self-construal on guilt arousal. That is, guilt appeals lead to higher guilt arousal for individuals with high independent rather than interdependent selfconstruals. However, the main effect of self-construal on shame arousal was not found. That is, shame appeals do not lead to higher shame arousal for individuals with high interdependent rather than independent self-construals.

Self-construal with referencing and sources of evaluation. For guilt, the interaction effect between SC and type of appeal was not statistically significant, $F(3,121)=.868, p=.460$. This indicates that there is no significant difference in the effect of referencing or sources of evaluation on GAr between IndSC and IntSC. There was also no statistically significant main effect for type of appeal, $F(3$, $121)=1.480, p=.224$; but there was statistically significant main effect for SC, $F(1,121)=4.779, p=.031$. This means that across all types of appeals (self-referenced versus other-referenced, internal versus external) guilt arousal scores do not differ, but these scores differ across self-construals (main effect). For shame, the interaction effect between SC and type of appeal was not statistically significant, $F(3,127)=1.033, p=.380$. This indicates that there is no significant difference in the effect of referencing or sources of evaluation on SAr between IndSC and IntSC. There were also no statistically significant main effects for SC, $F(1,127)=.256, p=.613$ or for type of appeal, $F(3,127)=.112, p=.953$. From the results, hypotheses $2(a, b)$ and $3(a, b)$ are rejected. Research questions $1(a, b)$ and $2(a, b)$ are confirmed: self-construal has no interactive effects with referencing or sources of evaluation on guilt/shame arousal elicited from a guilt/shame appeal.

This study did not find any interactive effects of self-construal with referencing or the sources of evaluation. It found that across types of appeals (self-referenced versus other-referenced guilt and shame, internal versus external guilt/shame), guilt and shame arousals respectively do not differ significantly.

\subsection{Study $1 B$}

\section{Method}

Measurements. The construct measurements, generated on the basis of operationalization and scales previously used in the literature adapted for this study context, used 7-point scales (see Appendix 2). As noted previously, study 1B used the same sample and dataset with study $1 \mathrm{~A}$. Thus, all measurements in both studies (1A: emotional arousal, self-construal; 1B: message compliance, personal cultural orientation) are included to test.

Measurement model. Structural equation models were used to test measurement and structural models. The results of the 


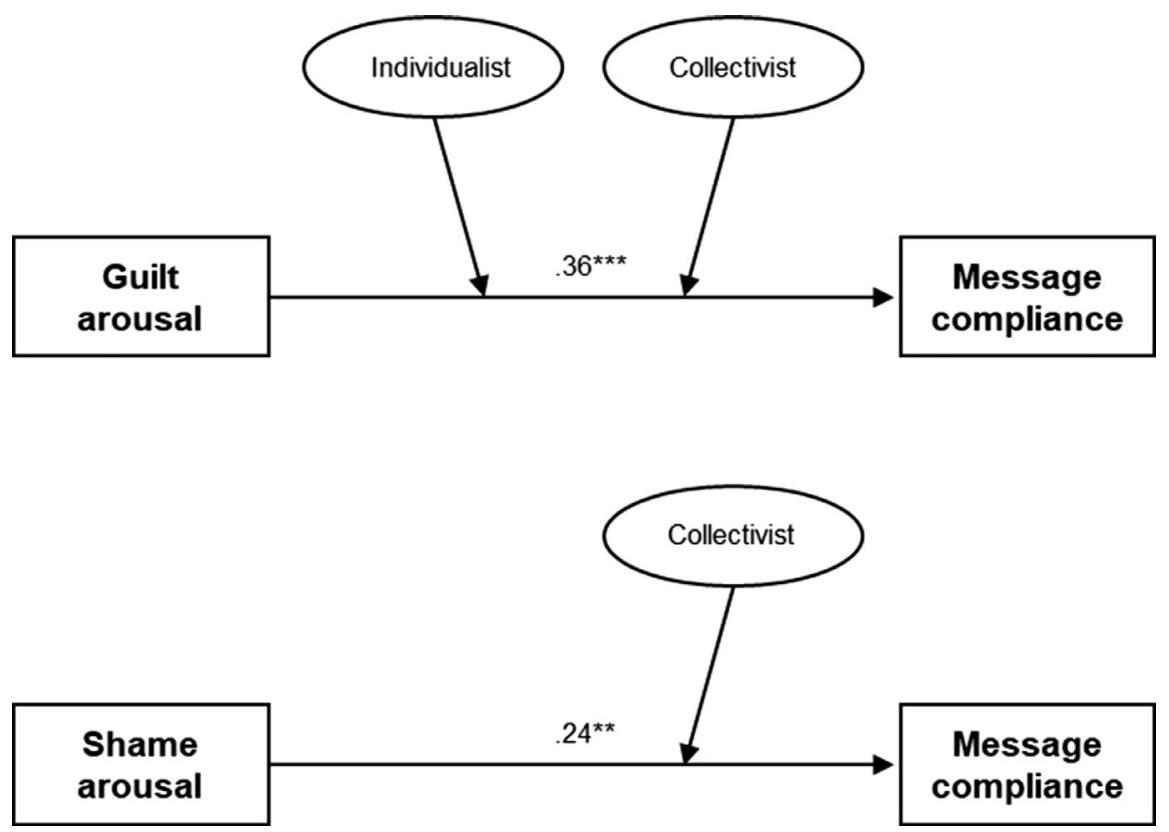

Fig. 1. Model path coefficients. Note. ${ }^{* *} p<.01,{ }^{* * *} p<.001$.

Table 2

Model fit Statistics for the final measurement model.

\begin{tabular}{lccccl}
\hline Measurement Model & $\chi^{2} / d f$ & TLI & CFI & sRMR & RMSEA \\
\hline Guilt model & 1.36 & .95 & .96 & .051 & $.052(.037-.066)$ \\
Shame model & 1.42 & .94 & .95 & .064 & $.056(.042-.069)$ \\
Overall model & 1.60 & .96 & .96 & .052 & $.048(.039-.056)$ \\
\hline
\end{tabular}

goodness-of-fit, reliability, convergent validity, and discriminant validity indicate that the fit of the overall measurement model is deemed acceptable (see Table 2).

The final overall measurement model (nested guilt and shame models) satisfactorily met the goodness-of-fit criteria: $\chi^{2} / \mathrm{d} f=1.60$; $\mathrm{TLI}=.96 ; \mathrm{CFI}=.96 ; \mathrm{sRMR}=.052 ; \mathrm{RMSEA}=.048$. The convergent validity of the measurement model was supported: the factor loadings of items were mostly greater than .70, AVE estimates of the constructs were greater than .60 , and construct reliability estimates all exceeded .80 .

The Fornell-Larcker criterion (Fornell and Larcker, 1981) and cross-loadings were used to evaluate discriminant validity. All the square root of AVE estimates were larger than the corresponding inter-construct correlation estimates and all bivariate correlations were less than .50. The Heterotrait-monotrait (HTMT) ratio of correlations (Henseler et al., 2015) using $H_{T M T} .85$ criterion was examined to further check for discriminant validity. All HTMT values were below the criterion (Table 3 ).

Results

Structural model (hypotheses testing). Both guilt and shame models had a good fit $\left(\chi^{2} / \mathrm{d} f=1.98, \mathrm{TLI}=.97, \mathrm{CFI}=.98, \operatorname{sRMR}=.067\right.$, RMSEA $=.087 ; \chi^{2} / \mathrm{d} f=1.84, \mathrm{TLI}=.97, \mathrm{CFI}=.98$, sRMR $=.044$, RM$\mathrm{SEA}=.073$, respectively).

Guilt and shame arousals. As shown in Fig. 1, GAr has a medium positive impact on message compliance (MC) $(\beta=.36, p<.001)$, $\mathrm{SAr}$ has a small positive impact on message compliance $(\beta=.24$, $p=.006)$. Therefore, hypothesis $4(\mathrm{a}, \mathrm{b})$ is accepted.

The findings of this study align with the linear effect studies on emotion and behavioral intention (Cotte et al., 2005; Lindsey, 2005; Turner and Underhill, 2012) and reveal that emotion plays a major role in determining behavioral change towards the health message (Xu and Guo, 2018). That is, guilt and shame arousals positively influence message compliance: the higher the emotional arousals, the greater the compliance with the health message.

Personal cultural orientation (PCO): Individualist (IndPCO) versus Collectivist (ColPCO). The path $\mathrm{SAr} \rightarrow \mathrm{MC}$ is significantly positive only for ColPCO $(\beta=.36, p=.004)$, but non-significant for IndPCO $(\beta=.12, p=.361)$. Hence, PCO moderates the relationship between shame arousal and message compliance. Specifically, the relationship is not significant for individualists but significant for collectivists. For comparison of means, after adjusting for SAr scores, there was no significant difference between IndPCO and ColPCO on MC, $F(1,133)=.248, p=.619$. Thus, hypothesis 5 is accepted: (a) individualist individuals experiencing shame are not significantly likely to comply with the message, whereas (b) collectivist individuals experiencing shame are likely to do so.

The path $\mathrm{GAr} \rightarrow \mathrm{MC}$ is significantly positive for each of these two PCOs (IndPCO: $\beta=.26, p=.000$; ColPCO: $\beta=.35, p=.000$ ). The path is not significantly different across IndPCO and ColPCO $\left(\Delta \chi^{2}(1)=1.102, p=.294\right)$. Thus, PCO does not moderate the relationship between GAr and MC. For comparison of means, after adjusting for GAr scores, there was no significant difference between IndPCO and ColPCO on MC, $F(1,127)=.600, p=.440$. Thus, research question 3 is confirmed: personal cultural orientation has no impact on the relationship of guilt arousal and message compliance.

The study found that personal cultural orientation moderates the effect of shame arousals on message compliance, but does not moderate the effect of guilt arousals on message compliance. In addition, no differences were found in message compliance levels between individualist and collectivist orientations, regardless of guilt or shame emotion type. That is, guilt predicted message compliance in both orientations, whereas shame only predicted message compliance in collectivists.

\section{General discussion and implications}

\subsection{Moderating effect of self-construal}

The findings provide support for the moderating effect of selfconstrual on guilt/shame arousal. Specifically, although the interactive effect with referencing or the source of evaluation on 
Table 3

\begin{tabular}{llllll}
\multicolumn{2}{l}{ Discriminant validity: Fornell-Larcker criterion and HTMT ratio. } \\
\hline Constructs & 1 & 2 & 3 & 4 & 5 \\
\hline 1. Emotional arousal & .91 & & & & \\
2. Message compliance & $.39(.39)$ &. $\mathbf{8 7}$ & & & \\
3. Independent self-construal & $.10(.13)$ & $.10(.14)$ &. $\mathbf{7 8}$ & & \\
4. Interdependent self-construal & $.17(.19)$ & $.11(.14)$ & $.36(.35)$ & $\mathbf{. 8 4}$ & \\
5. Personal cultural orientation & $.39(.38)$ & $.29(.28)$ & $.10(.12)$ & $.48(.58)$ & $\mathbf{. 7 6}$ \\
\hline
\end{tabular}

Note. Square root of AVEs in the diagonal; Implied correlations for each construct in the model in the lower half of the table; HTMT ratios in parentheses.

guilt/shame arousals was not found in the present study, the main effect of self-construal on guilt arousals was evident. As an individual characteristic, self-construal moderates the levels of guilt arousals from guilt appeals. Explicitly, independent self-construals experience higher guilt arousals than their interdependent counterparts when exposed to guilt appeals. This broadly supports the past studies in this area which found that there are various groups of self-construals with differing appraisals (Block, 2005; Martin et al., 2013; Park et al., 2011). The findings suggest that self-construal does have some impact on the relationship between emotional appeals and emotional arousals. This provides an insight when comparing the moderating effect of self-construal between guilt versus shame and contrasting this finding with the moderation effects towards emotional responses in general. This indicates that although guilt and shame are self-conscious emotions, when comparing guilt and shame in terms of distinct emotion, all selfconscious emotions are still not equally appraised by customers (Han et al., 2014). These findings provide insight into when guilt and shame have different effects on message processing.

The ability to understand the specific characteristics of different self-construals would enable marketers to incorporate these two self-conscious emotions into health messages to enhance persuasion. The findings of this study indicate that guilt appeals stimulate guilt arousals to the independent self-construals over the interdependent self-construals. The independents are motivated to promote self-responsibility that fosters the feelings of guilt when personal responsibility/accountability in guilt is more salient (Becheur et al., 2019). This has shaped a moderating effect of self-construal on moral judgments and suggests that independents were more likely to be influenced by feeling ego-focused (e.g., guilt, pride) than other-focused emotions (e.g., shame, anger) (Kim and Johnson, 2014). The findings also indicate that, in terms of shame arousals, based on shame appeals, self-construal has no mediation. For shame, emotional appeal is an equally better predictor of emotional arousal level for both self-construals. Consistent with the previous few studies that have directly measured self-construal, this result provides support for the premise that individuals high in interdependent self-construals, for whom social relationships are central to definitions of the self, would express more affective consequences in interpersonal contexts (e.g., shame) (Cross et al., 2011). Interestingly, independent self-construals are also found to be a better predictor of socially disengaging emotions (e.g., shame, anger) like interdependent self-construals (Xie et al., 2008). Although independence and interdependence differ, there is disagreement over whether they are, in fact, emotionally related to the same specific affective consequences (Kitayama et al., 2004). These misconceptions have emphasized self-construal differences in emotional feelings, which in turn could deter independent selfconstruals from complying with shame appeal messages.

The study examined self-construals to identify individuals as independents versus interdependents at the individual level. The study of self-construals has gained significance in the cultural psychology discipline (Cross et al., 2011), but there is much research comparing self-construals as stable cultural characteristics
(Block, 2005; Kim and Johnson, 2014) rather than dynamic individual characteristics. This study is the first attempt to this end and contributes to laying the groundwork for further analyses on self-construals as dynamic individual characteristics. Descriptions of two self-construals such as independent and interdependent self-construals can be utilized to help understand individuals' differences in terms of behavioral intentions.

\subsection{Interactive effect of self-construal with referencing and sources of evaluation}

The study's findings show that the interactive effect of self-construal with referencing or the source of evaluation on guilt/shame arousals was not evident. Specifically, levels of emotional arousal elicited from an emotional appeal were not impacted by any interaction of self-construal with referencing or the source of evaluation. The findings of the current research do not support the previous research which suggests that selfconstrual interacts with referencing to impact self-conscious emotional appeals processing (Aaker and Williams, 1998; Block, 2005; Wong and Tsai, 2007). For instance, Aaker and Williams (1998) examined the persuasive effects of ego-focused (e.g., pride) versus other-focused (e.g., empathy) emotional appeals across cultures and found that the self-reference effect was obtained for independent self-construals who viewed a pride emotional appeal. More specifically, Block's (2005) studies on fear and guilt appeals suggested that for individuals with independent construals, the selfreference compared to the other-reference effect is either advantageous or disadvantageous depending on the types of emotions (e.g., fear versus guilt). That is, for people who hold a predominantly independent self-construal, superiority of self-referencing over other-referencing holds for guilt appeals but not for fear.

One interpretation of this inconsistency is that a message's attributes of self-reference or internal source of evaluation based on focus towards the self (versus the others) or orientation to one's own standards/views (versus the others') are not salient to individuals with an independent view when processing the message. This is because independent individuals have sub-types (i.e., relational versus independent self-construal) that may vary effects on cognition, affect, and motivation (Cross et al., 2011). Further, the discrepancy could possibly be due to the measure of self-construals. In Block's (2005) studies the self-construals were measured by ethnic-level (American versus Asian), while in the present study they were measured by individual-level characteristics (independent versus interdependent individuals).

\subsection{Moderating effect of personal cultural orientation}

The results indicate that personal cultural orientation has a moderating effect on message compliance across guilt and shame. The impact of shame arousals on message compliance is moderated by personal cultural orientation. However, the same does not apply for guilt arousals. More specifically, shame arousals predict message compliance in only collectivist, not individualist, orientations; but guilt arousals predict message compliance 
in both orientations. This is consistent with previous predictions that guilt is more favorable for behavioral responses than shame (Abe, 2004; Ghorbani et al., 2013; Lindsay-Hartz, 1984). For individualists, when deciding on the level of compliance with the health message, shame was not a determinant of the amount, while on the contrary, guilt was a significant predictor of the level of message compliance.

Shame was not predictive of individualists' compliance, which is consistent with the literature on shame. Bagozzi et al. (2003) compared Dutch (i.e., national cultural individualism) and Filipino (i.e., national cultural collectivism) salespersons' experiences of shame as a consequence of customer actions. The real experience of shame was very similar for both groups, but the behavioral reactions were different. For Dutch employees shame diminished customer relationship-building, whereas for Filipino employees shame enhanced it. The link between shame and defensive reactions, such as running away and hiding from others (Tangney et al., 2007, 1992), is typical of individualistic cultures (Kitayama et al., 1995), where the sense of self as independent is valued and shame can be interpreted as a sign of weakness (Silfver-Kuhalampi, 2009). This might explain why shame does not predict message compliance for individualist individuals.

The current study investigated the role of personal cultural orientation in the effectiveness of guilt and shame appeal messages in order to know which condition, guilt or shame, is most effective. Most studies of guilt and shame have been proposed and tested across cultures based on ethnicity or nationality (Bagozzi et al., 2003; Lee and Paek, 2014). This study used personal cultural orientation (Yoo and Donthu, 2005) to identify message receivers as individualists or collectivists at the individual level. While it is argued that cultural differences are assumed to be consistent with individual differences within each of the cultures, these differences are not always reducible to individual differences (Na et al., 2010). Thus, this study furthers the understanding of with which personal cultural orientation people up-regulate or down-regulate these two emotions.

For managerial implications, the insights of self-construal and personal cultural orientation differences in message receivers can provide communication campaigners with a means for targeting audiences at their tactical level. The most obvious consideration is the selection of a segmentation basis by using these individual differences. Market segmentation is seen as an important component of many successful marketing strategies because it would identify specific characteristics of a segment essential for marketing communications to target. Segmentation for such guilt and shame appeals can be achieved through studying the media or technology habits of message receivers. A judgement can be made regarding the collectivism level of the target consumer of a media vehicle or website where the message is being considered on the basis of preferred content and featured articles (Martin et al., 2013). Thus, when the audiences are segmented on the basis of self-construal or personal cultural orientation, health communication campaigns that reflect, and are better suited to, the individualities of consumer behavior may then be considered. While the message characteristics are under the communication campaigner's control, it is possible to target specific audiences through the choice of media programmes/channels as communication vehicles.

\subsection{Differentiated effect of guilt versus shame}

This study found no significant difference in the effect of guilt versus shame emotions on message compliance. Specifically, guilt arousal and shame arousal are equal in predicting message compliance. The findings provide more empirical evidence of the effect of guilt versus shame emotions in persuasive communications. A review of the psychology literature shows that most of the prior studies found the differential effect of these two emotions (Abe, 2004; Graton et al., 2016; Lindsay-Hartz, 1984; Saintives and Lunardo, 2016; Stuewig et al., 2010; Tangney et al., 2007). However, this study did not find the differential effect of the emotion type on message compliance, based on the relationship between emotional arousal and message compliance. Therefore, the present study's findings not only support the notion that guilt tends to create more positive behaviors (Graton et al., 2016; Saintives and Lunardo, 2016; Tangney et al., 2007), but also critique both the rationale that shame is innately maladaptive (Abe, 2004; LindsayHartz, 1984; Stuewig et al., 2010) and the inverted U-shaped relationship between emotional appeals and behavioral intentions (Coulter et al., 1999; Coulter and Pinto, 1995; O'Keefe, 2002; Pinto and Worobetz, 1992). This discrepancy, however, can be attributed to the past studies evaluating emotional appeals instead of single emotional arousals (LaTour and Rotfeld, 1997). This current study, on the other hand, examined, separately, distinct guilt versus shame emotional arousals resulting from emotional appeals. As previously mentioned, a guilt appeal may actually evoke shame unintentionally or a combination of shame and guilt (Bennett, 1998; Boudewyns et al., 2013). By isolating the effect of an unintended emotion aroused from the appeal, the present study was able to discover that guilt and shame arousal via health communications is likely to be productive.

More importantly, the effect of guilt versus shame arousals on message compliance varies across personal cultural orientations. Explicitly, guilt arousals predict message compliance in all orientations, while shame arousals predict message compliance only in collectivist, not in individualist orientations. This study contributes to the extant literature as the first step of an empirical effort to probe the differential effects of guilt versus shame under moderating impacts such as individual differences in personal cultural orientation.

A significant contribution of this research lies in its focus on the health communications context and on the effectiveness of distinct types of emotions. Most past studies on the relationship between guilt appeals and behavioral intentions have been examined in pro-social and charitable donation behavior (Xu and Guo, 2018). As previously noted, there are differences among the pro-social or charitable donations and health communications contexts in terms of personal significance. The results add an additional aspect to the current literature by providing evidence that guilt and shame appeals operate differently due to the interaction between the selfconscious type of such emotions and the personal significance in the health communications context. The suggestion is that, even with the same type of emotions, their effectiveness apparently varies depending on the context. Such variations existing within self-conscious emotions appear to suggest that there may be the same or even more marked differences for other emotions. This outcome is important for theory building in discrete emotions and in other pro-social and pro-health contexts.

\section{Conclusion}

The present study has extended the understanding of the processes by which guilt and shame appeals lead to better message compliance, within the context of health communications. The results support the set of hypotheses that the degree to which message receivers aroused guilt or shame and their subsequent message compliance are functions of type of emotion, self-construal, and personal cultural orientation of individuals. Although the interactive effects of self-construal with referencing or the source of evaluation on emotional arousals were nonsignificant, the main effect of self-construal on guilt arousal was obtained. Consistently, personal cultural orientation moderates the relationship of emotional arousal and message compliance. 
As methodologically demonstrated, the value of this research is in the study of emotional arousal/response from the stimulus, not the stimulus/appeal itself. In traditional stimulus-response research, manipulation of guilt or shame was used to assess which emotion produced the greatest response and the role of the receiver's response was overlooked. That approach limited the practical generalizations beyond the stimulus materials and receivers of each particular study. With a standardized and developed model such as the one this study proposes, health marketers could assess individual messages and the most persuasive message would be the one that generates the greatest emotional arousal with a target segment.

\section{Limitations and future research}

The study has some limitations that should be taken into account when the findings are interpreted and applied. While this study can assist global practitioners, and anti-binge drinking efforts in particular, to develop health communications campaigns, the study's results are limited to New Zealand. Despite a multicultural blend within its population, individualists dominate in this country (Scollon et al., 2011). It is argued that in the case of personal cultural orientation, a one-size-fits-all approach may not apply. Thus, further advances in this area require investigating samples in Eastern countries.

An additional limitation is found in the research method of study. Although self-report measures are recommended for assessing emotional states, they only provide information about conscious experiences of aroused feelings of guilt and shame. Next, a longitudinal study investigating the differential long-term effects of guilt and shame appeals would also be desirable. Moreover, the nature of an undergraduate student sample with limited age range and educational level could also restrict the study's generalizability. Further, it is well known that attitudes and intentions are different from behaviors (Webb and Sheeran, 2006), thus future studies are encouraged to investigate the effectiveness of guilt and shame on actual behaviors, not simply behavioral intentions. Finally, the study's findings are limited by the fact that the same sample was used twice (Kaiser et al., 1999). Thus, the generalizability of the study must be examined in future research.

\section{Declaration of Competing interest}

None.

\section{CRediT authorship contribution statement}

Hoang Sinh Nguyen: Writing - original draft. Daniel Laufer: Supervision, Conceptualization. Jayne Krisjanous: Supervision, Conceptualization.

\section{Acknowledgments}

Portions of this study are based on the author's doctoral dissertation. Accordingly, he would like to thank his supervisors Associate Professor Daniel Laufer and Dr Jayne Krisjanous for their guidance and support. The author would also like to thank the anonymous reviewers, and the participants of the 2017 Global Conference of the American Academy of Advertising for their helpful advice and insightful comments. 


\section{Appendix A. Stimulus advertisements}

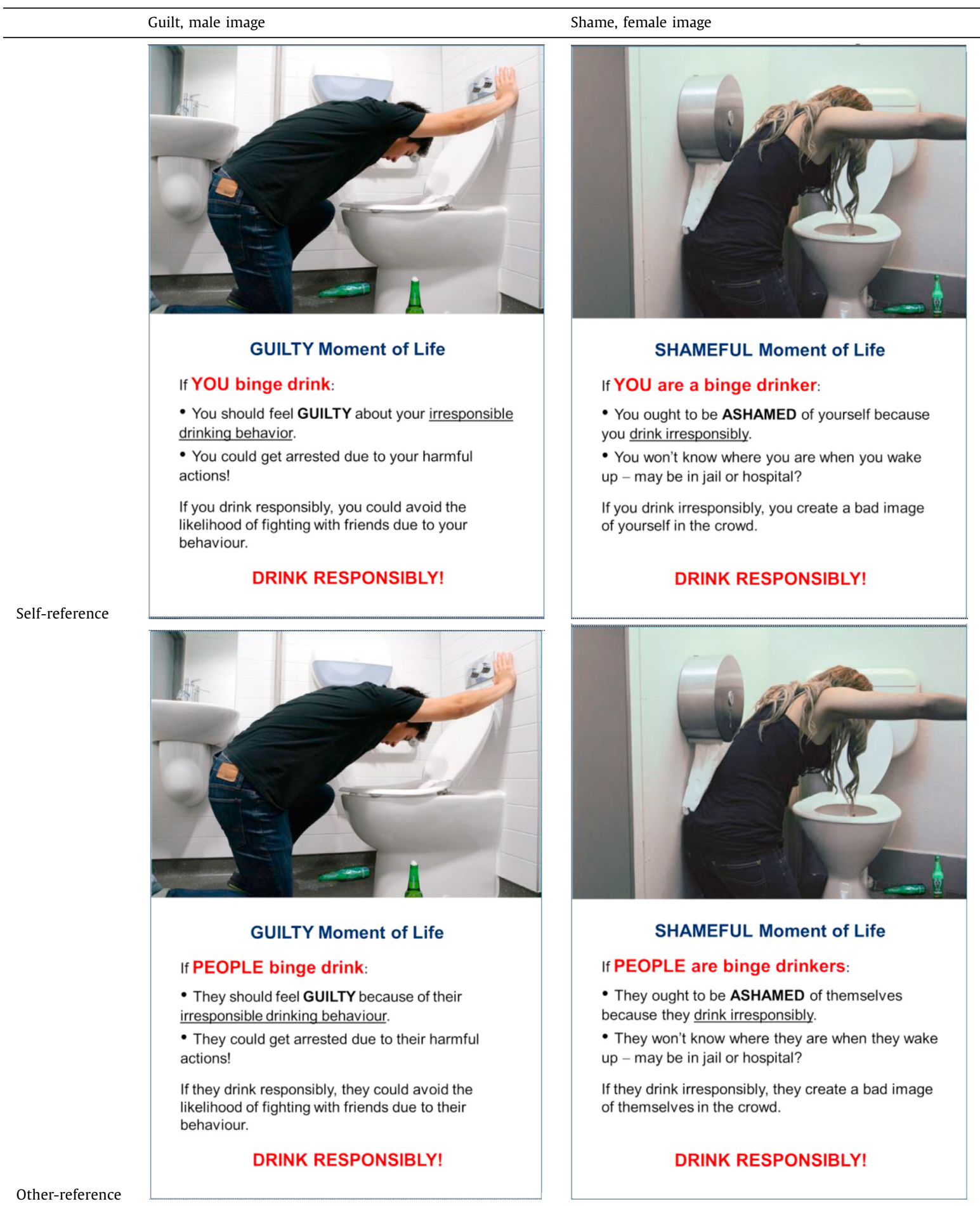

(continued on next page)

Please cite this article as: H.S. Nguyen, D. Laufer and J. Krisjanous, The effectiveness of guilt and shame appeals on health communications: The moderating role of self-construal and personal cultural orientation, Australasian Marketing Journal, https://doi.org/10.1016/j. ausmj.2020.08.002 


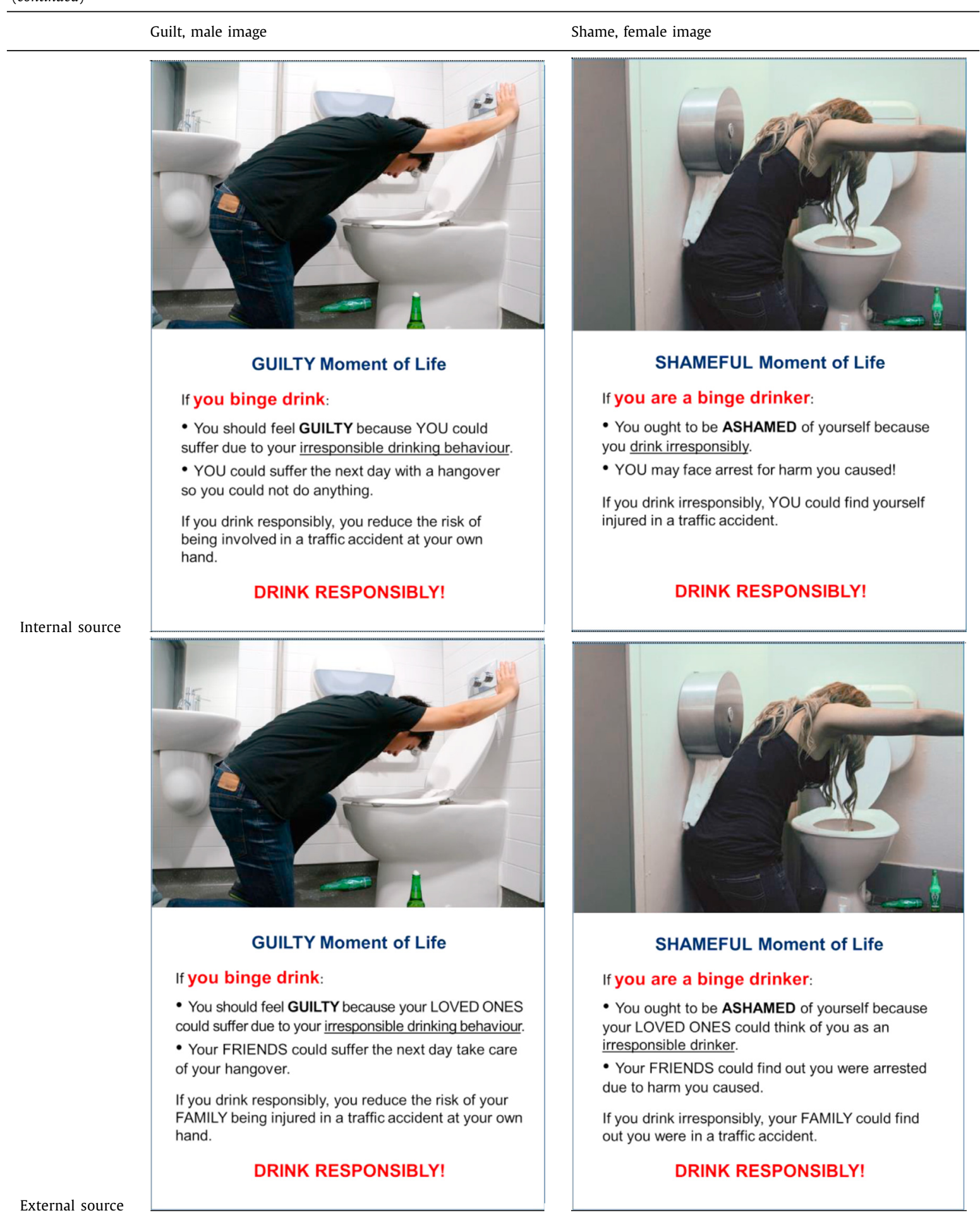




\section{Appendix B. Measurements of constructs}

\begin{tabular}{|c|c|c|}
\hline Constructs & Items & Sources \\
\hline Guilt arousal (GAr) & $\begin{array}{l}\text { 1. condemned; } 2 \text {. unethical; } 3 \text {. immoral; } 4 \text {. delinquent; } 5 \text {. unconscionable; } 6 \text {. inappropriate; } \\
\text { 7. wicked; } 8 \text {. criminal; } 9 \text {. liable; } 10 \text {. indecent; } 11 \text {. unscrupulous; } 12 \text {. imprudent }\end{array}$ & $\begin{array}{l}\text { Hoblitzelle (1987): } \\
\quad \alpha=.86 \text { for shame and }\end{array}$ \\
\hline Shame arousal (SAr) & $\begin{array}{l}\text { 1. bashful; 2. mortified; } 3 \text {. shy; } 4 \text {. humiliated; } 5 \text {. abashed; 6. embarrassed; } 7 \text {. depressed; } 8 \text {. } \\
\text { chided; } 9 \text {. reproached; } 10 \text {. ashamed }\end{array}$ & .88 for guilt \\
\hline $\begin{array}{l}\text { Message compliance } \\
\quad(\mathrm{MC})\end{array}$ & $\begin{array}{l}\text { 1. I intend to behave in ways that are consistent with the message.* } \\
\text { 2. I am going to make an effort to do what the message urged me to do. } \\
\text { 3. I plan to act in ways that are compatible with the position promoted by the message. }\end{array}$ & $\begin{array}{l}\text { Yu and Shen (2012): } \\
\quad \alpha=.96\end{array}$ \\
\hline $\begin{array}{l}\text { Independent } \\
\text { self-construal (IndSC) }\end{array}$ & $\begin{array}{l}\text { 1. I'd rather say "No" directly than risk being misunderstood. } \\
\text { 2. Speaking up in a work/task group/class is not a problem for me. } \\
\text { 3. Having a lively imagination is important to me. } \\
\text { 4. I am comfortable being singled out for praise or rewards. } \\
\text { 5. I am the same person at home that I am at school. } \\
\text { 6. Being able to take care of myself is a primary concern for me. } \\
\text { 7. I act the same way no matter who I am with. } \\
\text { 8. I feel comfortable using someone's first name soon after I meet them, even when they } \\
\text { are much older than I am. } \\
\text { 9. I prefer to be direct and forthright when dealing with people I've just met. } \\
\text { 10. I enjoy being unique and different from others in many respects. } \\
\text { 11. My personal identity, independent of others, is very important to me. } \\
\text { 12. I value being in good health above everything.* }\end{array}$ & $\begin{array}{l}\text { Singelis (1994): } \alpha=.76 \\
\text { and } .81 \text { for } \\
\text { independent and } \\
\text { interdependent } \\
\text { self-construal } \\
\text { (Park et al., 2011) }\end{array}$ \\
\hline $\begin{array}{l}\text { Interdependent } \\
\text { self-construal (IntSC) }\end{array}$ & $\begin{array}{l}\text { 1. I have respect for the authority figures with whom I interact. } \\
\text { 2. It is important for me to maintain harmony within my group. } \\
\text { 3. My happiness depends on the happiness of those in my group. } \\
\text { 4. I would offer my seat on the bus to my professor.* } \\
\text { 5. I respect people who are modest about themselves. } \\
\text { 6. I will sacrifice my self-interests for the benefit of the group I am in. } \\
\text { 7. I often have the feeling that my relationships with others are more important than my } \\
\text { own accomplishments. } \\
\text { 8. I should take into consideration my parents' advice when making education/career } \\
\text { plans. } \\
\text { 9. It is important to me to respect decisions made by my group. } \\
\text { 10. I will stay in a group if they need me, even when I'm not happy with the group. } \\
\text { 11. If my brother or sister fails, I feel responsible.* } \\
\text { 12. Even when I strongly disagree with group members, I avoid an argument.* }\end{array}$ & \\
\hline $\begin{array}{l}\text { Personal cultural } \\
\text { orientation (PCO) }\end{array}$ & $\begin{array}{l}\text { 1. Individuals should sacrifice self-interest for the group that they belong to. } \\
\text { 2. Individuals should stick with the group even through difficulties. } \\
\text { 3. Group welfare is more important than individual rewards. } \\
\text { 4. Group success is more important than individual success. } \\
\text { 5. Individuals should pursue their goals after considering the welfare of the group. } \\
\text { 6. Group loyalty should be encouraged even if individual goals suffer. }\end{array}$ & $\begin{array}{l}\text { Yoo and Donthu (2005): } \\
\alpha=.85 \text {, (Schumann } \\
\text { et al., 2010) }\end{array}$ \\
\hline
\end{tabular}

Note. ${ }^{*}$ Items removed from final scale due to low factor loading.

\section{References}

Aaker, J.L., 2000. Accessibility or diagnosticity? Disentangling the influence of culture on persuasion processes and attitudes. J. Consum. Res. 26 (4), 340-357.

Aaker, J.L., Lee, A.Y., 2001. "I" seek pleasures and "we" avoid pains: the role of self-regulatory goals in information processing and persuasion. J. Consum. Res. 28 (1), 33-49.

Aaker, J.L., Williams, P., 1998. Empathy versus pride: the influence of emotional appeals across cultures. J. Consum. Res. 25 (3), 241-261.

Abe, J.A., 2004. Shame, guilt, and personality judgment. J. Res. Pers. 38 (2), 85-104.

Agrawal, N., Duhachek, A., 2010. Emotional compatibility and the effectiveness of antidrinking messages: a defensive processing perspective on shame and guilt. J. Mark. Res. 47 (2), 263-273.

Alegria, M., Atkins, M., Farmer, E., Slaton, E., Stelk, W., 2010. One size does not fit all: taking diversity, culture and context seriously. Admin. Policy Mental Health Mental Health Serv. Res. 37 (1-2), 48-60.

Ang, S.H., Low, S.Y., 2000. Exploring the dimensions of ad creativity. Psychol. Mark. 17 (10), 835-854.

Arthur, D., Quester, P., 2003. The ethicality of using fear for social advertising. Australas. Mark. J. 11 (1), 12-27.

Backhaus, K.B., Stone, B.A., Heiner, K., 2002. Exploringthe relationship between corporate social performance and employer attractiveness. Bus. Soc. 41 (3), 292-318.

Bagozzi, R.P., Verbeke, W., Gavino, J.C., 2003. Culture moderates the self-regulation of shame and its effects on performance: the case of salespersons in the Netherlands and the Philippines. J. Appl. Psychol. 88 (2), 219-233.

Baumeister, R.F., Stillwell, A.M., Heatherton, T.F., 1994. Guilt: an interpersonal approach. Psychol. Bull. 115 (2), 243-267.

Becheur, I., Guizani, H., Shaaban, K., 2019. Belief in fate and self-efficacy in road safety advertising based on guilt: an explanation based on negotiable fate. Australas. Mark. J. 27 (4), 233-241.
Bennett, R., 1998. Shame, guilt and responses to non-profit and public sector ads. Int. J. Adv. 17 (3), 483-499.

Bennett, D.S., Sullivan, M.W., Lewis, M., 2005. Young children's adjustment as a function of maltreatment, shame, and anger. Child Maltreat. 10 (4), 311-323.

Block, L.G., 2005. Self-referenced fear and guilt appeals: the moderating role of self-construal. J Appl. Soc. Psychol. 35 (11), 2290-2309.

Boudewyns, V., Turner, M.M., Paquin, R.S., 2013. Shame-free guilt appeals: testing the emotional and cognitive effects of shame and guilt appeals. Psychol. Mark. 30 (9), 811-825.

Brennan, L., Binney, W., 2010. Fear, guilt, and shame appeals in social marketing. J. Bus. Res. 63 (2), 140-146.

Brommersma, J., 2007. A Charity's Marathon: Charity Advertising, The Telethon and Consumer Response. University of Nottingham.

Burnkrant, R.E., Unnava, H.R., 1995. Effects of self-referencing on persuasion. J. Consum. Res. 22 (1), 17-26.

Cotte, J., Coulter, R.A., Moore, M., 2005. Enhancing or disrupting guilt: the role of ad credibility and perceived manipulative intent. J. Bus. Res. 58 (3), 361-368.

Coulter, R.H., Cotte, J., Moore, M.L., 1999. Believe it or not: persuasion, manipulation and credibility of guilt appeals. Adv. Consum. Res. 26 (1), 288-294.

Coulter, R.H., Pinto, M.B., 1995. Guilt appeals in advertising: what are their effects. J. Appl. Psychol. 80 (6), 697-705.

Creighton, M.R., 1990. Revisiting shame and guilt cultures: a forty-year pilgrimage. Ethos 18 (3), 279-307.

Cross, S.E., Hardin, E.E., Gercek-Swing, B., 2011. The what, how, why, and where of self-construal. Pers. Soc. Psychol. Rev. 15 (2), 142-179.

Czub, T., 2013. Shame as a self-conscious emotion and its role in identity formation. Pol. Psychol. Bull. 44 (3), 245-253.

de Hoog, N., Stroebe, W., de Wit, J.B.F., 2005. The impact of fear appeals on processing and acceptance of action recommendations. Pers. Soc. Psychol. Bull. 31 (1), 24-33.

de Hooge, I.E., Zeelenberg, M., Breugelmans, S.M., 2010. Restore and protect motivations following shame. Cognit. Emot. 24 (1), 111-127. 
Dean, K.K., Fles, E.H., 2016. The effects of independent and interdependent self-construals on reactions to transgressions: distinguishing between guilt and shame. Self Identity 15 (1), 90-106.

Dickinson, S., Holmes, M., 2008. Understanding the emotional and coping responses of adolescent individuals exposed to threat appeals. Int. J. Adv. 27 (2), 251-278.

Dickinson, S.J., Holmes, M.D., 2011. Threat appeal communications: the interplay between health resistance and cognitive appraisal processes. J. Mark. Commun. 17 (2), 107-125.

Duhachek, A., Agrawal, N., Han, D., 2012. Guilt versus shame: coping, fluency, and framing in the effectiveness of responsible drinking messages. J. Mark. Res. 49 (6), 928-941.

Eid, M., Diener, E., 2001. Norms for experiencing emotions in different cultures: inter- and intranational differences. J. Pers. Soc. Psychol. 81 (5), 869-885.

Flora, J.A., Maibach, E.W., 1990. Cognitive responses to AIDS information: the effects of issue involvement and message appeal. Communic. Res. 17 (6), 759-774.

Folkman, S., Schaefer, C., Lazarus, R.S., 1979. Cognitive processes as mediators of stress and coping. In: Hamilton, V., Warburton, D.M. (Eds.), Human Stress and Cognition: An Information Processing Approach. Wiley, London, England, pp. 265-298.

Fornell, C., Larcker, D.F., 1981. Structural equation models with unobservable variables and measurement error: algebra and statistics. J. Mark. Res. 18 (3), 382-388.

Gausel, N., Brown, R., 2012. Shame and guilt-do they really differ in their focus of evaluation? Wanting to change the self and behavior in response to ingroup immorality. J. Soc. Psychol. 152 (5), 547-567.

Gausel, N., Leach, C.W., 2011. Concern for self-image and social image in the management of moral failure: rethinking shame. Eur. J. Soc. Psychol. 41 (4), 468-478.

Ghorbani, M., Liao, Y., Çayköylü, S., Chand, M., 2013. Guilt, shame, and reparative behavior: the effect of psychological proximity. J. Bus. Ethics 114 (2), 311-323.

Gilbert, P., 1998. What is shame? Some core issues and controversies. In: Gilbert, P.E., Andrews, B.E. (Eds.), Shame: Interpersonal Behavior, Psychopathology, and Culture. Oxford University Press, New York.

Gilbert, P., Bhundia, R., Mitra, R., McEwan, K., Irons, C., Sanghera, J., 2007. Cultural differences in shame-focused attitudes towards mental health problems in asian and non-asian student women. Ment. Health Relig. Cult. 10 (2), 127-141.

Graton, A., Ric, F., Gonzalez, E., 2016. Reparation or reactance? The influence of guilt on reaction to persuasive communication. J. Exp. Soc. Psychol. 62, 40-49.

Han, D., Duhachek, A., Agrawal, N., 2014. Emotions shape decisions through construal level: the case of guilt and shame. J. Consum. Res. 41 (4), 1047-1064.

Heine, S.J., Kitayama, S., Lehman, D.R., Takata, T., Ide, E., Leung, C., Matsumoto, H. 2001. Divergent consequences of success and failure in Japan and North America: an investigation of self-improving motivations and malleable selves. J. Pers. Soc. Psychol. 81 (4), 599-615.

Henseler, J., Ringle, C.M., Sarstedt, M., 2015. A new criterion for assessing discriminant validity in variance-based structural equation modeling. J. Acad. Mark. Sci. 43 (1), 115-135.

Hibbert, S., Smith, A., Davies, A., Ireland, F., 2007. Guilt appeals: persuasion knowledge and charitable giving. Psychol. Mark. 24 (8), 723-742.

Hoblitzelle, W., 1987. Differentiating and measuring shame and guilt: the relation between shame and depression. In: Lewis, H.B. (Ed.), The Role of Shame in Symptom Formation. Erlbaum, Hillsdale, NJ, pp. 207-235.

Hoek, J., Insch, A., 2011. Special section on marketing and public policy: going beyond a Nanny State (Editorial). Australas. Mark. J. 19 (3), 165-167.

Jefferis, B., Power, C., Manor, O., 2005. Adolescent drinking level and adult binge drinking in a national birth cohort. Addiction 100 (4), 543-549.

Johnston, K.L., White, K.M., 2003. Binge-drinking: a test of the role of group norms in the theory of planned behaviour. Psychol. Health 18 (1), 63-77.

Kaiser, F.G., Ranney, M., Hartig, T., Bowler, P.A., 1999. Ecological behavior, environmental attitude, and feelings of responsibility for the environment. Eur. Psychol. 4 (2), 59-74.

Kaufman, G., 1996. The Psychology of Shame: Theory and Treatment of Shame-Based Syndromes, 2nd ed. Springer Publishing Company, New York.

Keller, P.A., Lehmann, D.R., 2008. Designing effective health communications: a meta-analysis. J. Public Policy Mark. 27 (2), 117-130.

Keller, P.A., Lipkus, I.M., Rimer, B.K., 2003. Affect, framing, and persuasion. J. Mark. Res. 40 (1), 54-64.

Kim, J.-.E., Johnson, K.K.P., 2013. The impact of moral emotions on cause-related marketing campaigns: a cross-cultural examination. J. Bus. Ethics 112 (1), 79-90.

Kim, J.-.E., Johnson, K.K.P., 2014. Shame or pride? The moderating role of self-construal on moral judgments concerning fashion counterfeits. Eur. J. Mark. 48 (7/8), 1431-1450.

Kim, S., Thibodeau, R., Jorgensen, R.S., 2011. Shame, guilt, and depressive symptoms: a meta-analytic review. Psychol. Bull. 137 (1), 68-96.

Kitayama, S., Markus, H.R., Matsumoto, H., 1995. Culture, self, and emotion: a cultural perspective on "self-conscious" emotions. In: Tangney, J.P., Fischer, K.W. (Eds.), Self-conscious Emotions: The Psychology of Shame, Guilt, Embarrassment, and Pride. Guilford Press, New York, pp. 439-464.

Kitayama, S., Mesquita, B., Karasawa, M., 2006. Cultural affordances and emotional experience: socially engaging and disengaging emotions in Japan and the United States. J. Pers. Soc. Psychol. 91 (5), 890-903.

Kitayama, S., Snibbe, A.C., Markus, H.R., Suzuki, T., 2004. Is there any "free" choice? Self and dissonance in two cultures. Psychol. Sci. 15 (8), 527-533.

LaTour, M.S., Rotfeld, H.J., 1997. There are threats and (maybe) fear-caused arousal: theory and confusions of appeals to fear and fear arousal itself. J. Advert. 26 (3) 45-59.
Leary, M.R., Baumeister, R.F., 2000. The nature and function of self-esteem: sociometer theory. Psychol. Rev. 116 (2), 365-383.

Lee, C.K.-C., Brown, R., Blood, D., 2000. The effects of efficacy, cognitive rrocessing and message framing on persuasion. Australas. Mark. J. 8 (2), 5-17.

Lee, H., Paek, H.-.J., 2014. Roles of guilt and culture in normative influence: testing moderated mediation in the anti-secondhand smoking context. Psychol. Health. Med. 19 (1), 1-10.

Leshner, G., Bolls, P., Thomas, E., 2009. Scare'em or Disgust'em: the effects of graphic health promotion messages. Health Commun. 24 (5), 447-458.

Levinson, C.A., Langer, J.K., Rodebaugh, T.L., 2011. Self-construal and social anxiety: considering personality. Pers. Individ. Dif. 51 (3), 355-359.

Lewis, H.B., 1971. Shame and Guilt in Neurosis. International Universities Press, New York.

Lewis, M., 1992. Shame: The Exposed Self. The Free Press, New York.

Lindsay-Hartz, J., 1984. Contrasting experiences of shame and guilt. Am. Behav. Sci. 27 (6), 689-704.

Lindsey, L.L.M., 2005. Anticipated guilt as behavioral motivation: an examination of appeals to help unknown others through bone marrow donation. Hum. Commun. Res. 31 (4), 453-481.

Lord, C.G., 1980. Schemas and images as memory aids: two modes of processing social information. J. Pers. Soc. Psychol. 38 (2), 257-269.

Lwin, M., Phau, I., 2014. An exploratory study of existential guilt appeals in charitable advertisements. J. Mark. Manage. 30 (13-14), 1467-1485.

Markus, H.R., Kitayama, S., 1991. Culture and the self: implications for cognition, emotion, and motivation. Psychol. Rev. 98 (2), 224-253.

Martin, B., Lawson, R., 1998. Mood and framing effects in advertising. Australas Mark. J. 6 (1), 35-50.

Martin, B.A., Lee, C.K.C., Weeks, C., Kaya, M., 2013. How to stop binge drinking and speeding motorists: effects of relational-interdependent self-construal and self-referencing on attitudes toward social marketing. J. Consum. Behav. 12 (1) 81-90.

Meyers-Levy, J., Peracchio, L.A., 1996. Moderators of the impact of self-reference on persuasion. J. Consum. Res. 22 (4), 408-423.

Mills, R.S., 2005. Taking stock of the developmental literature on shame. Dev. Rev. 25 (1), 26-63.

Murray-Johnson, L., Witte, K., Liu, W., Hubbell, A.P., Sampson, J., Morrison, K., 2001 Addressing cultural orientations in fear appeals: promoting AIDS-protective behaviors among Mexican immigrant and African American adolescents and American and Taiwanese college students. J. Health Commun. 6 (4), 335-358.

Na, J., Grossmann, I., Varnum, M.E., Kitayama, S., Gonzalez, R., Nisbett, R.E., 2010 Cultural differences are not always reducible to individual differences. Proc. Natl. Acad. Sci. 107 (14), 6192-6197.

Netemeyer, R.G., Burton, S., Andrews, J.C., Kees, J., 2016. Graphic health warnings on cigarette packages: the role of emotions in affecting aadolescent smoking consideration and secondhand smoke beliefs. J. Public Policy Mark. 35 (1), 124-143.

O'Keefe, D.J., 2002. Guilt as a mechanism of persuasion. In: James, P.D., Michael, P. (Eds.), The Persuasion Handbook: Developments in Theory and Practice. Sage Publications, Thousand Oaks, pp. 329-344.

O'Malley, P.M., Johnston, L.D., Bachman, J.G., 1998. Alcohol use among adolescents Alcohol Res. Health World 22 (2), 85-93.

Park, I.J.K., Sulaiman, C., Schwartz, S.J., Kim, S.Y., Ham, L.S., Zamboanga, B.L., 2011 Self-construals and social anxiety among Asian American college students: testing emotion suppression as a mediator. Asian Am. J. Psychol. 2 (1), 39-50.

Parrott, R., 1995. Designing messages for behavioral inoculation. In: Parrott, R.L. Maibach, E. (Eds.), Designing Health Messages: Approaches from Communication Theory and Public Health Practice. Sage, Beverly Hills, CA, pp. 99-113.

Pechmann, C., Zhao, G., Goldberg, M.E., Reibling, E.T., 2003. What to convey in antismoking advertisements for adolescents: the use of protection motivation theory to identify effective message themes. J. Mark. 67 (2), 1-18.

Pinto, M.B., Worobetz, N.D., 1992. Note on guilt appeals in advertising: covariate effects of self-esteem andlocus of control. Psychol. Rep. 70 (1), 19-22.

Rogers, R.W., 1975. A protection motivation theory of fear appeals and attitude change. J. Psychol 91 (1) 93-114.

Sabini, J., Silver, M., 1997. In defense of shame: shame in the context of guilt and embarrassment. J. Theory Soc. Behav. 27 (1), 1-15.

Saintives, C., Lunardo, R., 2016. How guilt affects consumption intention: the role of rumination, emotional support and shame. J. Consum. Mark. 33 (1), 41-51.

Schoenbachler, D.D., Whittler, T.E., 1996. Adolescent processing of social and physical threat communications. J. Advert. 25 (4), 37-54.

Schore, A.N., 1998. Early shame experiences and infant brain development. In: Gilbert, P.E., Andrews, B.E. (Eds.), Shame: Interpersonal Behavior, Psychopathology, and Culture. Oxford University Press, New York.

Scollon, C.N., Koh, S., Au, E.W.M., 2011. Cultural differences in the subjective experience of emotion: when and why they occur. Soc. Personal. Psychol. Compass 5 (11), 853-864.

Sedikides, C., Green, J.D., 2000. On the self-protective nature of inconsistency-negativity management: using the person memory paradigm to examine self-referent memory. J. Pers. Soc. Psychol. 79 (6), 906-922.

Silfver-Kuhalampi, M., 2009. The Sources of Moral Motivation: Studies on Empathy, Guilt, Shame and Values. University of Helsinki.

Silfver, M., 2007. Coping with guilt and shame: narrative approach. J. Moral Educ. 36 (2), 169-183.

Singelis, T.M., 1994. The measurement of independent and interdependent self-construals. Pers. Soc. Psychol. Bull. 20 (5), 580-591.

Singelis, T.M., Sharkey, W.F., 1995. Culture, self-construal, and embarrassability. J. Cross Cult. Psychol. 26 (6), 622-644 
Stipek, D., Weiner, B., Li, K., 1989. Testing some attribution-emotion relations in the People's Republic of China. J. Pers. Soc. Psychol. 56 (1), 109-116.

Stuewig, J., Tangney, J.P., Heigel, C., Harty, L., McCloskey, L., 2010. Shaming, blaming, and maiming: functional links among the moral emotions, externalization of blame, and aggression. J. Res. Pers. 44 (1), 91-102.

Sznycer, D., Tooby, J., Cosmides, L., Porat, R., Shalvi, S., Halperin, E., 2016. Shame closely tracks the threat of devaluation by others, even across cultures. Proc. Natl. Acad. Sci. 113 (10), 2625-2630.

Tangney, J.P., 1998. How does guilt differ from shame? In: Bybee, J. (Ed.) Guilt and Children. Academic Press, San Diego, CA, pp. 1-17.

Tangney, J.P., Dearing, R.L., 2002. Shame and Guilt. The Guilford Press, New York.

Tangney, J.P., Stuewig, J., Mashek, D.J., 2007. Moral emotions and moral behavior. Annu. Rev. Psychol. 58 (1), 345-372.

Tangney, J.P., Wagner, P., Fletcher, C., Gramzow, R., 1992. Shamed into anger? The relation of shame and guilt to anger and self-reported aggression. J. Pers. Soc. Psychol. 62 (4), 669-675.

Tanner Jr., J.F., Hunt, J.B., Eppright, D.R., 1991. The protection motivation model: a normative model of fear appeals. J. Mark. 55 (3), 36-45.

Tracy, J.L., Robins, R.W., 2007a. Self-Conscious Emotions: Where Self And Emotion Meet. In: Sedikides, C., Spencer, S.J. (Eds.), The Self: Frontiers of Social Psychology. Psychology Press, New York, pp. 187-209.

Tracy, J.L., Robins, R.W., 2007b. The self in self-conscious emotions: a cognitive appraisal approach. In: Tracy, J.L., Robins, R.W., Tangney, J.P. (Eds.), The Self-Conscious Emotions: Theory and Research. Guilford Press, New York, pp. 3-20.

Turner, M.M., Underhill, J.C., 2012. Motivating emergency preparedness behaviors: the differential effects of guilt appeals and actually anticipating guilty feelings. Commun. Q. 60 (4), 545-559.
Wallbott, H.G., Scherer, K.R., 1995. Cultural determinants in experiencing shame and guilt. In: Tangney, J.P., Fischer, K.W. (Eds.), Self-Conscious Emotions: The Psychology of Shame, Guilt, Embarrassment, and Pride. Guilford Press, New York, pp. 465-487.

Webb, T.L., Sheeran, P., 2006. Does changing behavioral intentions engender hehavior change? A meta-analysis of the experimental evidence. Psychol. Bull. 132 (2), 249-268.

Williams, P., Aaker, J.L., 2002. Can mixed emotions peacefully coexist. J. Consum. Res. 28 (4), 636-649.

Wong, Y., Tsai, J., 2007. Cultural models of shame and guilt. In: Tracy, J., Robins, R. Tangney, J. (Eds.), The Self-Conscious Emotions: Theory and Research. Guilford Press, New York, pp. 209-223.

Xie, D., Leong, F.T., Feng, S., 2008. Culture-specific personality correlates of anxiety among Chinese and Caucasian college students. Asian J. Soc. Psychol. 11 (2), $163-174$.

Xu, Z., Guo, H., 2018. A meta-analysis of the effectiveness of guilt on health-related attitudes and intentions. Health Commun. 33 (5), 519-525.

Yoo, B., Donthu, N., 2005. The effect of personal cultural orientation on consumer ethnocentrism: evaluations and behaviors of US consumers toward Japanese products. J. Int. Consum. Mark. 18 (1-2), 7-44.

Yu, N., Shen, F., 2012. Benefits for me or risks for others: a cross-culture investigation of the effects of message frames and cultural appeals. Health Commun. 28 (2), 133-145. 